\title{
(6) Pancreas and Gastrointestinal Hormones
}

\author{
Seiji Narto, M. D. \\ Department of Internal Medicine, Juntendo \\ University School of Medicine
}

The study of the exocrine pancreas was carried out to investigate the control system between exocrine cell and endocrine cell, and the mechanism of basal secretion related with catecholamine. In clinical studies the pancreozymin-secretin test and simultaneous glucose tolerance test with the endocrine secretive response by IRI measurement were observed.

It is a well known fact that the exocrine pancreas is controlled by the gastrointestinal hormones. At the first step, gastrin secretes the gastric juice containing hydrochloric acid excreted from gastric mucosa. When this voluminous hydrochloric acid flow out to duodenal cavity, secretin may be excreted into blood circulation and stimulates the ductal epithelial cells and centroacinal cells of the pancreas. On the other hand, dietary fat and some amino acids stimulate the intestinal pancreozymin secretion, and the enzymeful pancreatic juice is secreted from the acinal cells, and at the same time the concentrated gallbladder bile is excreted by the contraction of the gallbladder. Regarding the gastric secretion, the autonomic nervous systems play an important part. Particularly, cephalic phase and vagal phase are remarkably observed. However, the both phases are hardly observed in a mechanism of the exocrine pancreas, and preferably both pancreozymin and secretin induced a voluminous secretion from pancreas tissues. Both hormones are purified and today they are put on the commercial base. Moreover, synthetic hormones are produced by some authors. But, by reasons of a difficulty in the immunobody production, especially in secretin an impossibility of the binding of radioactive iodine due to a lack of tyrosine, radioimmunoassay is not ordinarily used except in the Yallow's and Chey's laboratory. Clinically, pancreozymin and secretin are generally used as a $\mathrm{P}-\mathrm{S}$ test for diagnosis of pancreatic disease in Japan as well as in America and Europe.

Baylise and Starling reported secretin as a hormone in 1902. After only eight years, Masuyama experimented by the Walzer's secretin in 1910, and he emphasized its effect as a stimulant of exocrine pancreas and recognized its inhibitory effect to adrenal hormone. In 1911 Matsuo reported the secretin effect on the pancreas and effect of hydrochloric acid in the duodenum to excretion of pancreatic juice. But in 1925 Fukumaki made an objection to secrein effect because the extract from intestinal mucosa contained a quantity of choline like substance. From 1930 Nakagawa and collaborators studied the secretin effect and the physiochemical constitution of secretin, including the effect to the exocrine pancreas, to the component of pancreatic 
juice, to the vascular bed, to the blood sugar, to the other organs, and also to the intestinal movement or uterus contraction. On the other hand, choloecystokinin was extracted through purification of secretin by Ivy and Oldberg in 1928 and pancreozymin was recognized by Harper and Raper in 1943. Jorpes and Mutt decided that the pancreozymin and cholecystokinin are the same substance by their purified procedure. In 1962 Yamakawa, Iwata and I reported the gallbladder contraction by hormonal control on a special lecture at annual meeting of the Japan Gastroenterology Society.

Pancreozymin-secretin test:

Sun and Shay used the both pancreozymin and secretin to examine the pancreas exocrine function in 1960, and in Japan in 1964 Fujimoto, Aoyama, Yamakawa and I reported the pancreozymin-secretin test at the autumn meeting of Japan Gastroenterology Society. At the same time, Ishii, Takeuchi, Takebe, Yamagata, Ogiwara and Oda studied the pancreozymin-secretin test. In 1973 panel discussion was held at the annual meeting of Japan Pancreas Disease Association regarding the limit and evaluation of the pancreozymin-secretin test for a diagnosis of pancreatic diseases. In conclusion, the excellent merits of the pancreozymin-secretin test were recognized by many authors to estimate the pancreatic function. But it was also recognized that this test has no sufficient value for diagnosis of localized pancreatic lesions, especially pancreatic cancer and pancreatic cystic disease, because of reserved ability of exocrine pancreatic tissue and deficiency of the informations from pancreatic juice. To advance of this examination, it was noted that the timely pattern analysis of pancreozymin phase and secretin phase, determination of secretive ability of ${ }^{75} \mathrm{Se}-$ methionine, and direct collection of pancreatic juice by the endoscopic cannulation were necessary. Furthermore, the comparative studies of the pancreozymin-secretin test with the endoscopic cholangio-pancreas-ductgraphy or selective angiography and with the histological and electron microscopic findings are needed.

Problems of the exocrine pancreas:

In these days, because of the fact that the both endogenous pancreozymin and secretin have not been measured ordinarily, the endogenous control systems relating to the intestinal endocrine function for the pancreatic exocrine ability has not been made clear. However, glucagon inhibits the secretin effect on the exocrine pancreas through an intravenous administration in hog, dog, and possibly in man, and insulin indirectly accelerates the lasting effect of secretin. On the other hand, pancreozymin induced the contraction of the gallbladder as well as the intestinal muscles. This effect would be suspected to be related to the outflow mechanism of bile and pancreatic juice into duodenum, where each fluid flows out on a rhythmic movement of Vater's papilla with simultaneously occurring rhythmic intestinal movement. When $1 \mathrm{mg}$ streptozotocin was administered for 5 days intraperitoneally in rat, the B cells of endocrine system were damaged with marked hyperglycemia. By the incubation method, it was recognized that the amylase releasing from this pancreatic slice was distinctly decreased. But the amylase was secreted from this pancreatic slice by 
adding pancreozymin in the medium, even when injured B cells were present. When glucagon was injected intraperitoneally to albino rat 30 minutes before killing, the amylase release into the medium from the pancreatic slice was decreased. Glucagon inhibits the amylase secretion in vitro as well as in vivo experiment. Recently, Hashimoto reported that DOPA and DOPamine induced the pancreatic secretion. Nakajima and I recognized the similar secretin effect, supporting that a kinetics of the exocrine pancreas is related with catecholamine system. The electronmicroscopic studies were carried out by above-mentioned stimulants and compared study with the physiological observation was made. All zymogen granules shifted to acinal cavity after administration of pylocarpin and acinal cells became clear at once with widened endoplasmic reticulum. In the comparison with those findings, pancreozymin moved the zymogen granules to acinal cavity and ribosome increased in acinal cells. Interestingly, certain cells became clear and others did not, suggesting that the dark cells were a proceeding situation of the production of zymogen granules or in a pause of secretion preparing for successive stimulation. Adrenalin and DOPamine did not move the zymogen granules but microvilli of acinal cavity were stretched and swollen.

Conclusion :

The mechanism of the exocrine pancreas is regulated through an action of gastrointestinal hormones, mainly pancreozymin and secretin excreted from basal cells of intestinal mucosa, and may be correspondent with the secretion of glucagon and insulin. Furthermore, it may be related with catecholamine metabolism. A large quantity of pancreatic juice is produced by both pancreozymin and secretin and a basal secretion of exocrine pancreas and sensibility of secretion may be regulated by catecholamine. The pancreozymin-secretin test was evaluated with distinguished merits for diagnosis of chronic pancreatic disease in about $80 \%$. But its value was low in localized lesion such as cancer of pancreas tail or small cancer. Glucose tolerance test with IRI response can be a subsidiary proceduce for diagnosis of pancreatic function. 